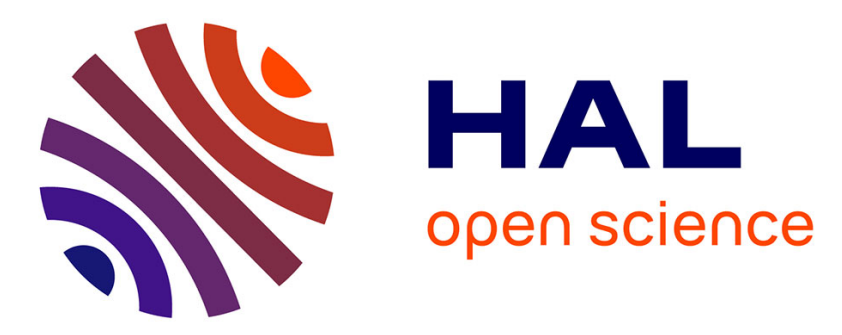

\title{
Interplay between non-bridging oxygen, triclusters, and fivefold Al coordination in low silica content calcium aluminosilicate melts
}

\author{
N. Jakse, M. Bouhadja, J. Kozaily, J. Drewitt, L. Hennet, D. Neuville, H. \\ Fischer, V. Cristiglio, Alain Pasturel
}

\section{To cite this version:}

N. Jakse, M. Bouhadja, J. Kozaily, J. Drewitt, L. Hennet, et al.. Interplay between non-bridging oxygen, triclusters, and fivefold $\mathrm{Al}$ coordination in low silica content calcium aluminosilicate melts. Applied Physics Letters, 2012, 101 (20), 10.1063/1.4766920 . insu-01906152

HAL Id: insu-01906152

https://hal-insu.archives-ouvertes.fr/insu-01906152

Submitted on 26 Oct 2018

HAL is a multi-disciplinary open access archive for the deposit and dissemination of scientific research documents, whether they are published or not. The documents may come from teaching and research institutions in France or abroad, or from public or private research centers.
L'archive ouverte pluridisciplinaire HAL, est destinée au dépôt et à la diffusion de documents scientifiques de niveau recherche, publiés ou non, émanant des établissements d'enseignement et de recherche français ou étrangers, des laboratoires publics ou privés. 


\section{Interplay between non-bridging oxygen, triclusters, and fivefold Al coordination in low silica content calcium aluminosilicate melts}

N. Jakse, M. Bouhadja, J. Kozaily, J. W. E. Drewitt, L. Hennet, D. R. Neuville, H. E. Fischer, V. Cristiglio, and A. Pasturel

Citation: Appl. Phys. Lett. 101, 201903 (2012); doi: 10.1063/1.4766920

View online: https://doi.org/10.1063/1.4766920

View Table of Contents: http://aip.scitation.org/toc/apl/101/20

Published by the American Institute of Physics

\section{Articles you may be interested in}

Structural and dynamic properties of calcium aluminosilicate melts: A molecular dynamics study

The Journal of Chemical Physics 138, 224510 (2013); 10.1063/1.4809523

Structure and properties of sodium aluminosilicate glasses from molecular dynamics simulations

The Journal of Chemical Physics 139, 044507 (2013); 10.1063/1.4816378

Striking role of non-bridging oxygen on glass transition temperature of calcium aluminosilicate glass-formers

The Journal of Chemical Physics 140, 234507 (2014); 10.1063/1.4882283

Structural, vibrational, and elastic properties of a calcium aluminosilicate glass from molecular dynamics simulations: The role of the potential

The Journal of Chemical Physics 141, 024507 (2014); 10.1063/1.4886421

Structural properties of a calcium aluminosilicate glass from molecular-dynamics simulations: A finite size effects study

The Journal of Chemical Physics 120, 10172 (2004); 10.1063/1.1724815

Structure and diffusion in amorphous aluminum silicate: A molecular dynamics computer simulation

The Journal of Chemical Physics 120, 384 (2004); 10.1063/1.1630562

\section{Lake Shore} CRYOTRONICS

\section{Sensors, Controllers, Monitors} from the world leader in cryogenic thermometry 


\title{
Interplay between non-bridging oxygen, triclusters, and fivefold Al coordination in low silica content calcium aluminosilicate melts
}

\author{
N. Jakse, ${ }^{1}$ M. Bouhadja, ${ }^{1}$ J. Kozaily, ${ }^{2,3}$ J. W. E. Drewitt, ${ }^{2, a)}$ L. Hennet, ${ }^{2}$ D. R. Neuville, ${ }^{4}$ \\ H. E. Fischer, ${ }^{3}$ V. Cristiglio, ${ }^{3}$ and A. Pasturel ${ }^{1}$ \\ ${ }^{1}$ Laboratoire Sciences et Ingénierie, Matériaux et Procédés (SIMAP), UMR CNRS 5266, Grenoble-INP, BP \\ 75, 38402 Saint Martin d'Hères Cedex, France \\ ${ }^{2}$ Conditions Extrêmes et Matériaux : Haute Température et Irradiation (CEMHTI), Id avenue de la \\ Recherche, Scientifique, 45071 Orléans cedex 2, France \\ ${ }^{3}$ Institut Laue Langevin, 6 rue Jules Horowitz, BP48 Grenoble cedex 9, France \\ ${ }^{4}$ CNRS-Institut de Physique du Globe de Paris, Sorbonne Paris Cité, 1 rue Jussieu, 75005 Paris cedex 05, \\ France
}

(Received 28 July 2012; accepted 26 October 2012; published online 13 November 2012)

\begin{abstract}
In the present work the structural properties of low silica content calcium aluminosilicate melts with concentration ratio $\mathrm{CaO} / \mathrm{Al}_{2} \mathrm{O}_{3}=1$ are investigated in the liquid and undercooled states by neutron diffraction experiments and ab initio molecular dynamics simulations. The results show the presence of $\mathrm{AlO}_{5}$ units and triclusters as well as non-bridging oxygen in the fully charge balanced compositions. Moreover, our findings allow us to identify a possible interplay between these structural units. Finally, we discuss the influence of these defective structural units on the properties of tetrahedral network and more particularly their implication on the evolution of the viscosity and the fragility. (C) 2012 American Institute of Physics. [http://dx.doi.org/10.1063/1.4766920]
\end{abstract}

Calcium aluminosilicate, $\mathrm{CaO}-\mathrm{Al}_{2} \mathrm{O}_{3}-\mathrm{SiO}_{2}$ (CAS) glasses, and melts are of technological and scientific interest. Their good optical and mechanical properties ${ }^{1,2}$ as well as their refractory nature make them attractive for a wide range of industrial applications such as nuclear and industrial waste storage, cements, ceramics, and industrial glasses. They are of fundamental importance in geosciences as they form a significant fraction of the composition of geologic magmas and their thermodynamic and dynamic properties show a strong dependence with the microscopic structure. ${ }^{3}$ An emerging concept relating to the structure of CAS compositions involves the interpenetration of two tetrahedral network glass formers, namely, $\mathrm{SiO}_{2}$ and $\mathrm{Al}_{2} \mathrm{O}_{3}$ with strong $\mathrm{Si}-\mathrm{O}$ and $\mathrm{Al}-\mathrm{O}$ bonds, containing another cation $(\mathrm{Ca})$ having the ability to compete with $\mathrm{Al}$ and $\mathrm{Si}$ for oxygen bonding. ${ }^{4}$ However, the detailed mechanisms and connection with the macroscopic properties are currently not well understood.

CAS glasses and melts with low silica content are of particular interest. Although glasses formed in the binary calcium aluminate $\mathrm{CaO}-\mathrm{Al}_{2} \mathrm{O}_{3}(\mathrm{CA})$ system exhibit exceptional sapphire-like optical properties, ${ }^{5}$ they readily devitrify. When a small amount of silica is added to CA, the narrow range of compositions (around $60 \%-70 \%$ of $\mathrm{CaO}$ ) where $\mathrm{CA}$ forms a glass by conventional quenching technique is substantially broadened. ${ }^{6-8}$ It has been shown that some properties such as the glass transition temperature are strongly related to the silica concentration. ${ }^{9,10}$ It has been hypothesized these changes might arise from non bridging oxygen (NBO) located on $\mathrm{SiO}_{4}$ tetrahedral units ${ }^{7}$ or from a greater polymerization due to the addition of silica. ${ }^{8}$ The knowledge of the structural origins of these changes at the atomic level is therefore of great interest.

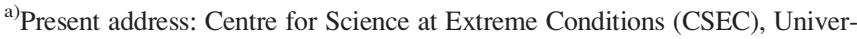
sity of Edinburgh, Mayfield Road, Edinburgh EH9 3JZ, United Kingdom.
}

In this letter, we address the important questions of the structural properties for low-silica content CAS melts, namely $\left(\mathrm{CaO}-\mathrm{Al}_{2} \mathrm{O}_{3}\right)_{1-x}\left(\mathrm{SiO}_{2}\right)_{x}$ for $x<0.2$, and their evolution with the silica composition $x$ along the ratio $\mathrm{CaO} / \mathrm{Al}_{2} \mathrm{O}_{3}$ equal to one, all these compositions being fully chargebalanced. For this purpose, we have combined neutron diffraction (ND) experiments using aerodynamic levitation and laser heating with $a b$ initio molecular dynamics simulations (AIMD). No experiment or simulation has been reported so far for these systems. In this study, results obtained with the composition $x=0.12$ (denoted Ca12.44) and $x=0.19$ (Ca19.40) are compared to our previous work on the composition $x=0(\mathrm{Ca} 0.50){ }^{11,12}$ More details on the sample preparation and composition can be found in Neuville et al. ${ }^{9} \mathrm{We}$ have obtained detailed information on the fractional distribution of coordination numbers $(\mathrm{CN})$ for $\mathrm{Si}, \mathrm{Al}$, and $\mathrm{Ca}$ atoms, bond-angle distributions, and concentration of non-bridging oxygen, $\mathrm{AlO}_{5}$ units, and triclusters, as well as their evolution with $\mathrm{SiO}_{2}$ composition and temperature. A decrease of the non-bridging oxygen and five-fold coordinated $\mathrm{Al}$ atoms is found, which is a clear indication of the reinforcement of the tetrahedral network with implications for the evolution of the viscosity and hence the fragility of the system.

ND experiments were carried out at the D4c instrument at the Institut Laue Langevin (ILL) in Grenoble (France). This two-axis neutron diffractometer, described in detail in Ref. 13, is dedicated to the structural determination of liquid and amorphous systems. In this study we used a working wavelength of $0.4969 \AA$, and the diffracted beam was measured over a $1.3^{\circ}-135^{\circ}$ angular range corresponding to a Q-range of $0.3-23.2 \AA^{-1}$. For studying the liquid state, we used the levitation setup integrated into the instrument and fully described in Ref. 14. Briefly, a spherical sample, $2.5 \mathrm{~mm}$ in diameter, is placed on a levitator that contains a convergent-divergent nozzle enabling the diffusion of a 
regulated gas flow onto the sample from below. This guaranties that the sphere remains in a stable position without any contact with the nozzle. The sample is melted using two $\mathrm{CO}_{2}$ lasers directed from the top and one from the bottom through the hole in the nozzle. The temperature is measured with a pyrometer working at $0.85 \mu \mathrm{m}$, and several video cameras are used to monitor the sample during the heating process. The experimental temperature is $T=1923 \mathrm{~K}$ both for Ca12.44 and Ca19.40. Some details of the data refinement are given in Ref. 15. The treatment includes the usual corrections for the background contribution and attenuation as well as multiple and inelastic scattering and a normalization using a diffraction measurements from a spherical vanadium reference sample with the same size.

AIMD simulations were performed in the canonical ensemble $(\mathrm{NVT})^{16}$ with $N=256$ atoms. The electronic structure calculations were performed within the density functional theory (DFT) using the generalized gradient approximation (GGA). ${ }^{17}$ We have used the Vienna ab initio simulation package $(\mathrm{VASP})^{18}$ in which the interaction between the ions and electrons is described by the projector augmented-wave (PAW) method, as implemented by Kresse and Joubert. ${ }^{19}$ Only the $\Gamma$-point has been used to sample the Brillouin zone. The size of the simulation box was fixed to reproduce the experimental density ${ }^{20}$ of the two CAS melts, namely $0.073 \AA^{-3}$ and $0.071 \AA^{-3}$, respectively, for Ca12.44 and Ca19.40. The number of atoms of each species is $33 \mathrm{Ca}$, $149 \mathrm{O}, 66 \mathrm{Al}$, and $8 \mathrm{Si}$ for composition Ca12.44 and $29 \mathrm{Ca}$, $151 \mathrm{O}, 58 \mathrm{Al}$, and $18 \mathrm{Si}$ for composition Ca19.40. Equations of motion are integrated using the Verlet algorithm in the velocity form with a time step of $1.5 \mathrm{fs}$. Such a small time step is needed to accurately capture the vibrational motion especially for $\mathrm{O}$ atoms. Initially the atoms are randomly distributed, and for both compositions the system is heated to $T=4000 \mathrm{~K}$ then cooled down to $T=2000 \mathrm{~K}$, with a cooling rate of $10^{13} \mathrm{~K} / \mathrm{s}$, above their melting temperatures $\left(T_{m}=1893 \mathrm{~K}\right.$ and $1823 \mathrm{~K}$ for Ca12.44 and Ca19.40, respectively). In order to examine the temperature dependence of the structural properties, the two systems were further cooled down to $T=1600 \mathrm{~K}$, deep in the undercooled region, at a rate of $10^{13} \mathrm{~K} / \mathrm{s}$ using the same densities. In each case, after an equilibration period of $6 \mathrm{ps}$ the simulation was continued during $20 \mathrm{ps}$ to determine the structural properties. The pressures recorded in the simulation cells are $0.56 \mathrm{GPa}$ for Ca12.44 and 0.67 GPa for Ca19.40 at $T=2000 \mathrm{~K}$, and they reduce to $0.25 \mathrm{GPa}$ and $0.36 \mathrm{GPa}$ at $T=1600 \mathrm{~K}$. The AIMD phase space trajectories were then analyzed using the ISAACS program $^{21}$ in order to determine structure factors, pair-correlation functions and resulting coordination numbers, as well as cluster statistics.

Figure 1 displays the neutron weighted average structure factor $S(Q)$ of $\left(\mathrm{CaO}-\mathrm{Al}_{2} \mathrm{O}_{3}\right)_{1-x}\left(\mathrm{SiO}_{2}\right)_{x}$ for $x=0,0.12$, and 0.19 , compared to the AIMD curves. For $x=0$, the simulation results are those of Cristiglio et al. ${ }^{12}$ which were performed at $T=2100 \mathrm{~K}$. The simulation and experimental results are in good agreement for all compositions. Small differences are seen at low $Q$ that we attribute to some finite size effects resulting from the small simulation boxes used. By increasing the silica content, an enhancement of the first sharp diffraction peak (FSDP) around $Q=2 \AA^{-1}$ is clearly

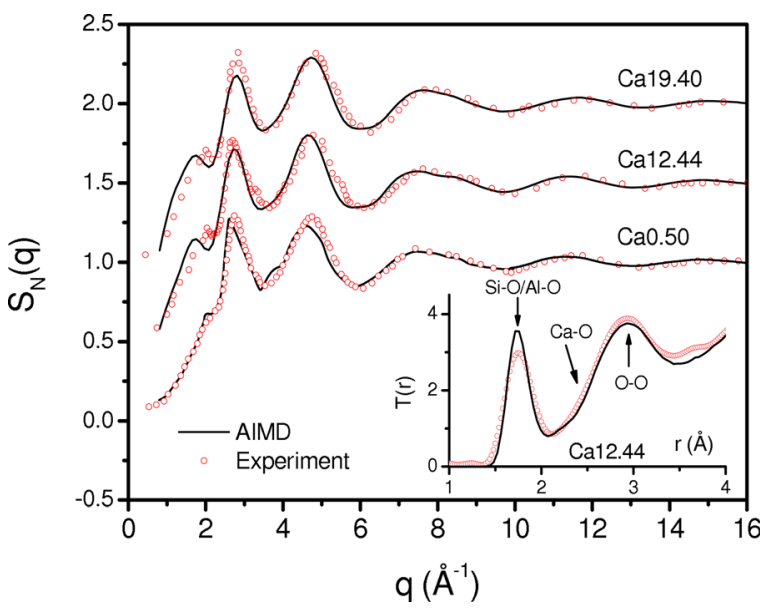

FIG. 1. (a) Total structure factors for $\left(\mathrm{CaO}-\mathrm{Al}_{2} \mathrm{O}_{3}\right)_{1-x}\left(\mathrm{SiO}_{2}\right)_{x}$ melts for $x=0,0.12$, and 0.19 . The red open circles are weighted average neutron scattering experiments, and the black lines correspond to AIMD results. The curves for $x=0.12$ and 0.19 are shifted by an amount of 0.5 and 1 , respectively, for clarity. The inset shows the function $T(r)$ for the composition Ca12.44. The symbols and line have the same meaning as the main panel.

visible and could be attributed to a strengthening of network formed with $\mathrm{AlO}_{4}$ and $\mathrm{SiO}_{4}$ tetrahedra. Interestingly, the position of the FSDP shifts towards small Q almost linearly (see Table I). The AIMD reproduces this trend consistently albeit with smaller $\mathrm{Q}$ values.

We come now to the determination of the structural properties of the network forming ( $\mathrm{Al}$ and $\mathrm{Si}$ ) and the modifier $(\mathrm{Ca})$ elements through the characteristics of the $\mathrm{Al}-\mathrm{O}, \mathrm{Si}-\mathrm{O}$, and $\mathrm{Ca}-\mathrm{O}$ bonds. Table I details the corresponding first neighbor distances and Table II the coordination numbers. The experimental values have been extracted from Gaussian fits to $T(r)=4 \pi \rho r g(r)$, where $g(r)$ is the total neutron weighted average pair-correlation function and $\rho$ the number density. $T(r)$ for the experiment and AIMD is presented in the inset of Fig. 1 in the case of Ca12.44. A very good agreement is seen albeit the first peak is a bit more structured. We can see that the $\mathrm{Ca}-\mathrm{O}$ correlations are only visible as a shoulder on the low $r$ side of the peak corresponding to $\mathrm{O}-\mathrm{O}$ bonds. Similar observations can be made with $x=0.19$. From a Gaussian fit to $T(r)$ it is then difficult to determine accurately the $\mathrm{Ca}-\mathrm{O}$ bond length and coordination number $\mathrm{CN}^{\mathrm{Ca}-\mathrm{O}}$ due to a large overlap with the neighboring peaks ( $\mathrm{Al}-\mathrm{O}$ and $\mathrm{O}-\mathrm{O}$ ). In Table I, we reported the $\mathrm{Ca}-\mathrm{O}$ distances estimated with an error of $\pm 0.05 \AA$. A large error bar of \pm 1 prevents any accurate experimental determination of $\mathrm{CN}^{\mathrm{Ca}-\mathrm{O}}$ (not reported in Table II). This difficulty has been also mentioned in previous neutron diffraction works, ${ }^{12}$ pointing out the need of simulations. Experimentally, the use a more selective technique like neutron

TABLE I. Position $Q$ of the FSDP $\left(\AA^{-1}\right), \mathrm{Si}-\mathrm{O}, \mathrm{Al}-\mathrm{O}$, and $\mathrm{Ca}-\mathrm{O}$ bond length $(\AA)$ for experiment (expt.) and AIMD (FP).

\begin{tabular}{|c|c|c|c|c|c|c|c|c|}
\hline & \multicolumn{2}{|c|}{$Q$} & \multicolumn{2}{|c|}{$r^{\mathrm{Si}-\mathrm{O}}$} & \multicolumn{2}{|c|}{$r^{\mathrm{Al}-\mathrm{O}}$} & \multicolumn{2}{|c|}{$r^{\mathrm{Ca}-\mathrm{O}}$} \\
\hline & Expt. & FP & Expt. & $\mathrm{FP}$ & Expt. & $\mathrm{FP}$ & Expt. & FP \\
\hline $\mathrm{Ca} 0.50$ & 2.09 & 2.00 & & & 1.79 & 1.80 & 2.32 & 2.30 \\
\hline Ca12.44 & 2.03 & 1.94 & 1.66 & 1.63 & 1.79 & 1.75 & 2.34 & 2.30 \\
\hline Ca19.40 & 1.99 & 1.73 & 1.66 & 1.63 & 1.79 & 1.75 & 2.34 & 2.32 \\
\hline
\end{tabular}


TABLE II. Average coordination numbers for $\mathrm{Si}-\mathrm{O}$, Al-O, and $\mathrm{Ca}-\mathrm{O}$ bonds. Numbers in parenthesis are for the undercooled states.

\begin{tabular}{|c|c|c|c|c|c|}
\hline & \multicolumn{2}{|c|}{$\mathrm{CN}^{\mathrm{Si}-\mathrm{O}}$} & \multicolumn{2}{|c|}{$\mathrm{CN}^{\mathrm{Al}-\mathrm{O}}$} & \multirow{2}{*}{$\frac{\mathrm{CN}^{\mathrm{Ca}-\mathrm{O}}}{\mathrm{FP}}$} \\
\hline & Expt. & FP & Expt. & FP & \\
\hline $\mathrm{Ca} 0.50$ & & & 4.20 & 4.10 & 6.20 \\
\hline Ca12.44 & 4.12 & 4.00 & 4.15 & 4.07 (4.04) & $6.00(6.08)$ \\
\hline Ca19.40 & 4.05 & 4.00 & 4.10 & $4.10(4.06)$ & $6.24(6.09)$ \\
\hline
\end{tabular}

diffraction with isotopic substitution will make a more accurate determination of the local order around $\mathrm{Ca}$ atoms possible. From the simulation results, the values of the distances are determined more precisely from the partial pair-correlation functions (not shown), and the coordination numbers are obtained by counting the number of $\mathrm{O}$ atoms in the atomic configurations within a cutoff corresponding to the first minimum in the corresponding pair-correlation functions $(2.2 \AA$ for $\mathrm{Si}-\mathrm{O}$, $2.5 \AA$ for $\mathrm{Al}-\mathrm{O}$, and $3.3 \AA$ for $\mathrm{Ca}-\mathrm{O}$ ). The $\mathrm{Si}-\mathrm{O}, \mathrm{Al}-\mathrm{O}$, and $\mathrm{Ca}-\mathrm{O}$ first neighbor distances are in good agreement for all the compositions and do not show a particular evolution with addition of $\mathrm{SiO}_{2}$. For all the compositions, the coordination numbers calculated from AIMD simulations are consistent with the experiment; however, a departure is noticeable for the $\mathrm{Ca}-\mathrm{O}$ bond but remains within the error bars.

A more detailed analysis of the effect on the coordination number distributions with the addition of silica can be made from the AIMD simulation results for the compositions $x=0.12$ and 0.19 . For $\mathrm{Si}-\mathrm{O}$ bonds, the formation of $\mathrm{SiO}_{5}$ or $\mathrm{SiO}_{3}$ units is always very rare in our simulations, and it is well-known that $\mathrm{Si}$ is essentially in four fold coordination on the tectosilicate join of aluminosilicate melts system. In contrast, the $\mathrm{CN}^{\mathrm{Al}-\mathrm{O}}$ and $\mathrm{CN}^{\mathrm{Ca}-\mathrm{O}}$ and bond-angle distributions given in Figures 2 and 3, respectively, show that the addition of silica perturbs the $\mathrm{Ca}$ and $\mathrm{Al}$ environment.
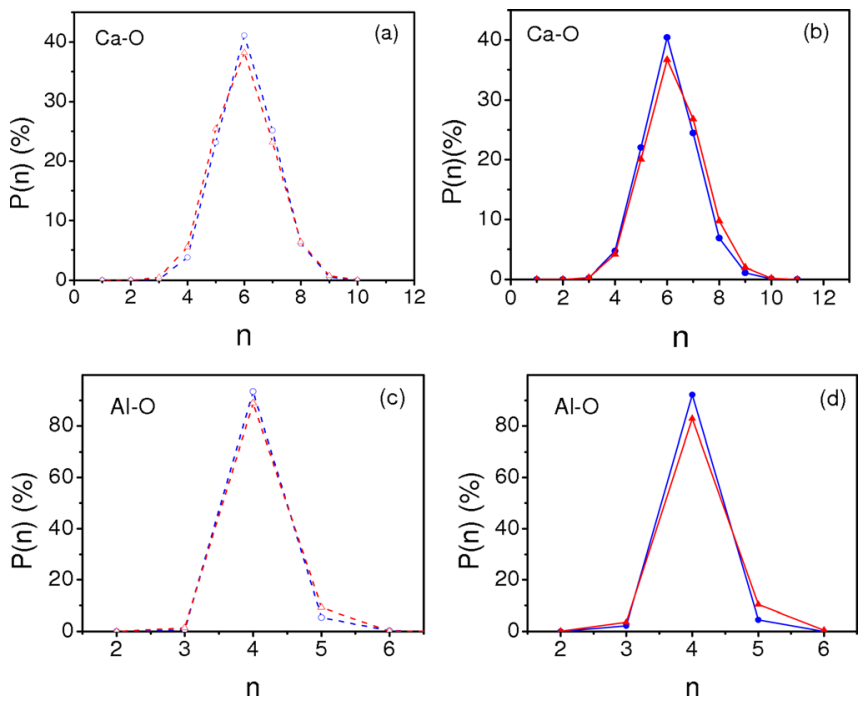

FIG. 2. Distributions of coordination numbers for $\mathrm{Al}-\mathrm{O}$ and $\mathrm{Ca}-\mathrm{O}$ bonds. (a),(c) for Ca12.44 and (b),(d) for Ca19.40. The open and full triangles are for the melts above the melting point while open and full circles correspond to the undercooled melts.

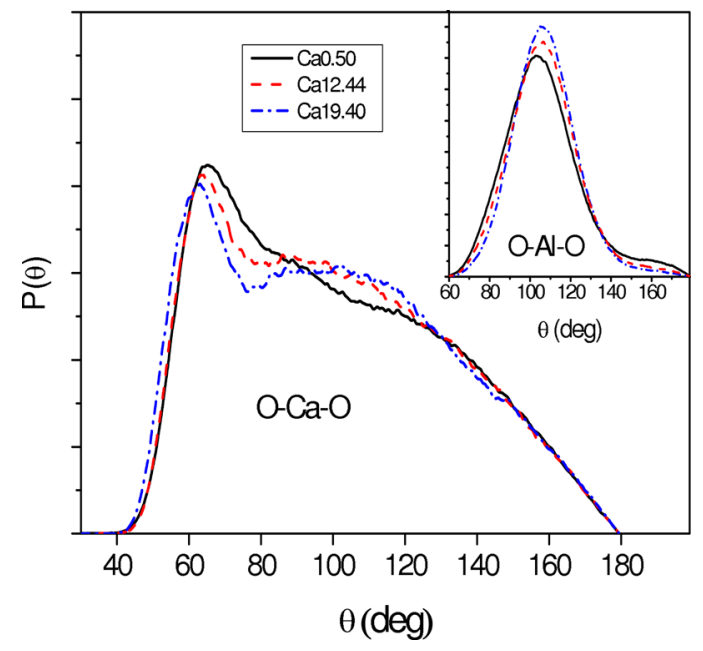

FIG. 3. Bond-angle distribution $\mathrm{O}-\mathrm{Ca}-\mathrm{O}$ (main panel) and for $\mathrm{O}-\mathrm{Al}-\mathrm{O}$ (inset) in the liquid state $(2100 \mathrm{~K}$ for $\mathrm{Ca} 0.50$ and $2000 \mathrm{~K}$ for $\mathrm{Ca} 12.44$ and Ca19.40). The results for Ca0.50 are those of Ref. 18 .

The $\mathrm{Ca}-\mathrm{O}$ bonds display a rather broad distribution ranging from 4- to 8-fold coordinated polyhedra, centered on 6-fold coordination. The $\mathrm{O}-\mathrm{Ca}-\mathrm{O}$ bond-angle distribution shown in Fig. 3 displays a main peak around $65^{\circ}$ and a large distribution above $80^{\circ}$. This is consistent with a superposition of cubic symmetries with specific angles of 70.5, 109.5, and $141^{\circ}$ and octahedral symmetry with angles at $90^{\circ}$. The fact that the distributions do not have marked peak above $80^{\circ}$ also reflects the disordered nature of melts with defective octahedral and cubic sites with 5- and 7-fold coordinated $\mathrm{Ca}$ atoms and therefore a complex environment.

For Al-O bonds, a large majority of $\mathrm{Al}$ atoms form $\mathrm{AlO}_{4}$ tetrahedral units (see Figure 3); however, a significant proportion of $\mathrm{AlO}_{5}$ units are present, as shown in Fig. 2. They represent $18 \%$ with respect to the total number of $\mathrm{Al}$ atoms for $\mathrm{Ca} 0.50$ (Ref. 12) and reduce to about $10 \%$ for $\mathrm{Ca} 12.44$ and $\mathrm{Ca} 19.40$, with the addition of $\mathrm{SiO}_{2}$. When melts are cooled below their melting temperature, the fraction of $\mathrm{AlO}_{5}$ polyhedra reduce to $5.4 \%$ and $4.5 \%$, respectively, for the $\mathrm{Ca} 12.44$ and $\mathrm{Ca} 19.40$. With respect to the total number of oxygen, the $\mathrm{AlO}_{5}$ represent $8 \%$ for $\mathrm{Ca} 0.50$ and reduce with the addition of $\mathrm{SiO}_{2}$ to about $4.4 \%$ for $\mathrm{Ca} 12.44$ and $3.9 \%$ for $\mathrm{Ca} 19.40$. In the undercooled states, the fraction of $\mathrm{AlO}_{5}$ polyhedra amounts to $2.4 \%$ and $1.7 \%$, respectively, for the Ca12.44 and Ca19.40. These values in the undercooled state are close to the experimental observations in the glassy states. ${ }^{5}$ We mention that the $\mathrm{O}-\mathrm{Al}-\mathrm{O}$ bond angle distributions, shown in the inset of Figure 3, display a preponderant tetrahedral peak and smaller one around $160^{\circ}$ which is a signature of the presence of $\mathrm{AlO}_{5}$ units. The decrease of the latter peak with increasing silica composition is consistent with the reduction of the fivefold $\mathrm{Al}$ coordination numbers.

The present simulations also show the formation of oxygen triclusters, namely three-fold coordinated oxygen atoms with $3 \mathrm{Al}, 2 \mathrm{Al}$ and $1 \mathrm{Si}, 1 \mathrm{Al}$ and $2 \mathrm{Si}$, or $3 \mathrm{Si}$ atoms without restrictions on the geometrical nature of the local environment around the three cations linked to them. For the compositions investigated we found mostly $\mathrm{OAl}_{3}$ triclusters. For liquid $\mathrm{Ca} 12.44$ the proportion of $\mathrm{O}$ atoms in triclusters reduces from $14.1 \%$ in the liquid to $12.2 \%$ in the undercooled 
state. For Ca19.40, the proportions are $14.2 \%$ in the liquid reducing to $10.7 \%$ in the undercooled state. The presence of significant quantities of both $\mathrm{AlO}_{5}$ species and oxygen triclusters reveals the complex nature of the Al-O network. ${ }^{22}$ Our findings show, however, that the $\mathrm{Al}_{2} \mathrm{O}_{3}$ tetrahedral network becomes better defined upon undercooling.

As mentioned above, the presence of non-bridging oxygen has important implications on the thermal and dynamic properties of the CAS glasses and melts. Ca atoms have the ability to create NBO by breaking $\mathrm{Si}-\mathrm{O}$ and/or Al-O bonds and therefore to weaken the tetrahedral network. The mechanisms involved in the occurrence of NBO have been reported by Stebbins and co-workers ${ }^{23,24}$ for CAS with high silica content and were linked to the viscosity by Neuville et al. ${ }^{25}$ A first one proposed in the seminal work of Stebbins and $\mathrm{Xu}^{23}$ is the production of $\mathrm{NBO}$ from the transformation of two BO in interaction with $\mathrm{Ca}$ network modifier cations. This reaction leads also to the formation of triclusters. The second one concerns consumption reactions of NBO to produce $\mathrm{AlO}_{5}$ units. $^{24}$ The NBO occur not only when $\mathrm{Ca}$ atoms are in excess with charge balancing (i.e., one $\mathrm{Ca}^{2+}$ that compensates two $\mathrm{AlO}_{4}^{-}$tetrahedral units) but also in perfect charged-balanced compositions. ${ }^{23,26}$ Such a trend implies that the number of NBO cannot be predicted only with simple stochiometric arguments for charge balancing. Here, the $\mathrm{CA}$ and both CAS compositions are fully charge balanced and our simulations firmly establish the presence of NBO. The latter have been obtained by counting the number of oxygen atoms that have only one $\mathrm{Si}$ or one $\mathrm{Al}$ atom and also one $\mathrm{Ca}$ atom in their first neighbor shell (the cutoff distances defined above have been used). The distributions of the number of NBO in Ca12.44 and Ca19.40 above and below the melting point are shown in Figure 4. In all cases, the calculated distributions show that the scenario in which no NBO are present does not occur in our simulations.

Above the melting point, NBO have a broad distribution centered at 18 and show only a slight decrease with composition between $x=0.12$ and 0.19 . They represent about $12 \%$ of the total number of oxygen, respectively. The number of NBO for $\mathrm{CaO} .50,{ }^{12}$ which represents $12.8 \%$, is in line with

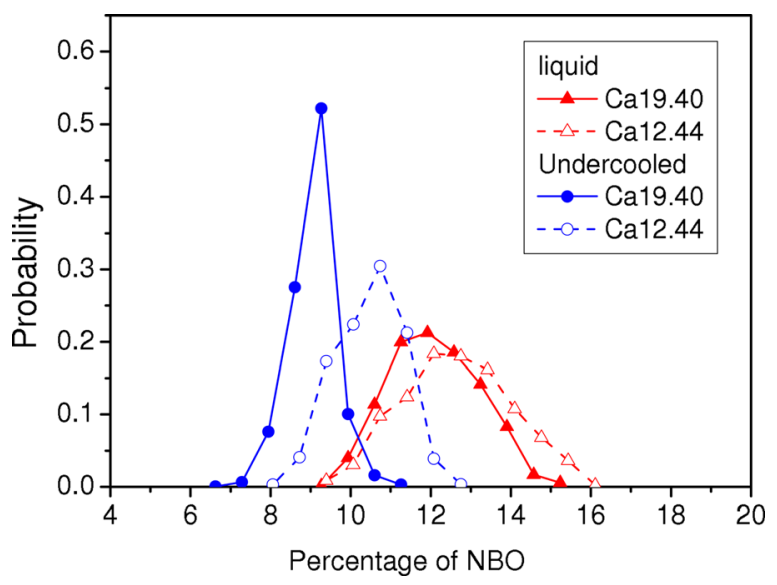

FIG. 4. Distribution of the number of non-bridging oxygen for Ca12.44 above the melting point (open red triangles) and in the undercooled melts (open red circles) as well as for CAS19.40 above the melting point (solid red triangles) and in the undercooled melts (solid red circles). The lines are guides for the eyes.
Ca12.44 and Ca19.40. Upon undercooling, our simulations reveal narrower distributions with a reduction of the average number of NBO, which evolves from $10.5 \%$ to $9.1 \%$, respectively, from $x=0.12-0.19$. The number of NBO found with classical molecular dynamics simulations by Cormier et al., ${ }^{27}$ who have reported $12.5 \%$ NBO in Ca12.44 glass, is consistent with our results. While in the liquid the evolution of NBO is small and probably hidden by thermal fluctuations, in the undercooled state a clear reduction is seen with increasing $\mathrm{SiO}_{2}$ concentrations. It should be mentioned that the reduction is consistent with the decrease of $\mathrm{Ca}$ content, where $\mathrm{Ca}$ cations act as network modifiers. Moreover, a reduction of the NBO with temperature occurs jointly with the reduction of triclusters and $\mathrm{AlO}_{5}$. In the undercooled state, the proportions found for triclusters is roughly the sum of those for $\mathrm{NBO}$ and $\mathrm{AlO}_{5}$. Such a result suggests for CAS with low silica content that NBO and triclusters are mainly formed according to the rule proposed by Stebbins and $\mathrm{Xu},{ }^{23}$ and the $\mathrm{AlO}_{5}$ units are formed through a consumption reaction of a part of the produced NBO. ${ }^{24}$ These mechanisms also hold at higher temperature, in the stable liquid; however, the proportions indicate that some $\mathrm{AlO}_{5}$ could also form independently of the two other species.

In summary, we have studied the structural properties of calcium aluminosilicate melts with low silica content namely $\left(\mathrm{CaO}-\mathrm{Al}_{2} \mathrm{O}_{3}\right)_{1-x}\left(\mathrm{SiO}_{2}\right)_{x}$ for $x=0,0.12$, and 0.19 . For this purpose, we have performed neutron diffraction experiments using aerodynamic levitation and laser heating combined with $a b$ initio molecular dynamics simulations to obtain detailed information on coordination numbers and bond angle distributions, and the presence of $\mathrm{AlO}_{5}$ species, oxygen triclusters, and non-bridging oxygen atoms. Their evolution with $\mathrm{SiO}_{2}$ concentrations and temperature has been examined. The structural analysis reveals (i) the presence of a significant amount of $\mathrm{AlO}_{5}$ units that decreases with temperature, giving rise to a reinforcement of the $\mathrm{Al}-\mathrm{O}$ tetrahedral network; (ii) the presence of NBO for these fully charged balanced CAS melts. Above the melting point the NBO show only a small evolution with composition due to thermal fluctuations, while they show a substantial decrease in the undercooled region.

More interestingly, the number of NBO, and to a smaller extent the proportion of $\mathrm{AlO}_{5}$, decrease with increasing $\mathrm{SiO}_{2}$ concentration in the undercooled state. NBO sites can be considered as broken links in the tetrahedral networks ${ }^{23}$ and five-coordinated entities are thought to serve as transition units that both favor microscopic diffusion and flow in CAS systems. ${ }^{25,28-30}$ Their abundance thus represents an important factor that impacts the viscosity in the liquid state. ${ }^{31}$ The reduction of both the $\mathrm{NBO}$ and $\mathrm{AlO}_{5}$ with increasing $\mathrm{SiO}_{2}$ concentration found in the present work should therefore increase the viscosity and relaxation times and hence decrease the fragility. ${ }^{32}$ It should be of great interest to study the fragility of these CAS melts in more detail and also with higher $\mathrm{SiO}_{2}$ content in the stable and undercooled states in connection with the presence of $\mathrm{NBO}$ and $\mathrm{AlO}_{5}$. This can be done experimentally by combining quasi-elastic neutrons and $\mathrm{x}$-ray scattering techniques using aerodynamic levitation. ${ }^{33}$ On the theoretical side, such a systematic study would greatly benefit from the use of efficient empirical potentials. Further work along these lines is currently in progress. 
We acknowledge the CINES and IDRIS under Project No. INP2227/72914 as well as PHYNUM CIMENT for computational resources. The ANR is gratefully acknowledged for financial support under Grant No. NT09 432740.

${ }^{1}$ M. E. Lines, J. B. MacChesney, K. B. Lyons, A. J. Bruce, A. E. Miller, and K. Nassau, J. Non-Cryst. Solids 107, 251 (1989).

${ }^{2}$ F. T. Wallenberger and S. D. Brown, Compos. Sci. Technol. 51, 243 (1994).

${ }^{3}$ B. O. Mysen, Structure and Properties of Silicate Melts (Elsevier, Amsterdam, 1988).

${ }^{4}$ A. Navrotski, K. L. Geikinger, P. McMillan, and G. V. Gibbs, Phys. Chem. Miner. 11, 284 (1985).

${ }^{5}$ Y.-M. Sung and S.-J. Kwon, J. Mater. Sci. Lett. 18, 1267 (1999).

${ }^{6}$ J. E. Shelby, J. Am. Ceram. Soc. 68, 155-158 (1985).

${ }^{7}$ P. L. Highby, R. J. Ginther, I. D. Aggarwal, and E. J. Friebele, J. NonCryst. Solids 126, 209-215 (1990).

${ }^{8}$ D. A. Dutt, P. L. Highby, and D. L. Griscom, Phys. Chem. Glasses 33, 51-55 (1992).

${ }^{9}$ D. R. Neuville, L. Cormier, A. M. Flank, P. Lagarde, and D. Massiot, Chem. Geol. 213, 153 (2004).

${ }^{10}$ L. Cormier, D. R. Neuville, and G. Calas, J. Am. Ceram. Soc. 88, 2292 (2005).

${ }^{11}$ J. W. E. Drewitt, S. Jahn, V. Cristiglio, A. Bytchkov, M. Leydier, S. Brassamin, H. E. Fischer, and L. Hennet, J. Phys.: Condens. Matter 23, 155101 (2011).

${ }^{12}$ V. Cristiglio, L. Hennet, G. J. Cuello, I. Pozdnyakova, M. Leydier, J. Kozaily, H. E. Fischer, M. R. Johnson, and D. L. Price, J. Non-Cryst. Solids 356, 2492-2496 (2010).

${ }^{13}$ H. E. Fischer, G. J. Cuello, P. Palleau, D. Feltin, A. C. Barnes, Y. S. Badyal, and J. M. Simonson, Appl. Phys. A 74, S160 (2002).

${ }^{14}$ L. Hennet, I. Pozdnyakova, A. Bytchkov, V. Cristiglio, P. Palleau, H. E. Fischer, G. J. Cuello, M. Johnson, P. Melin, D. Zanghi, S. Brassamin, J.-F.
Brun, D. L. Price, and M.-L. Saboungi, Rev. Sci. Instrum. 77, 053903 (2006).

${ }^{15}$ G. J. Cuello, J. Phys.: Condens. Matter 20, 244109 (2008).

${ }^{16} \mathrm{~A}$ Nose thermostat is used to control the temperature, see S. Nosé, J. Chem. Phys. 81, 511 (1984).

${ }^{17}$ Y. Wang and J. P. Perdew, Phys. Rev. B 44, 13298 (1991).

${ }^{18}$ G. Kresse and J. Furthmüller, Comput. Mater. Sci. 6, 15 (1996); Phys. Rev. B 54, 11169 (1996).

${ }^{19}$ G. Kresse and D. Joubert, Phys. Rev. B 59, 1758 (1999).

${ }^{20}$ P. Courtial and D. B. Dingwell, Geochim. Cosmochim. Acta 59, 3685 (1995).

${ }^{21}$ S. Le Roux and V. Petkov, J. Appl. Cryst. 43, 181 (2010).

${ }^{22}$ D. R. Neuville, L. Cormier, and D. Massiot, Chem. Geol. 229, 173 (2006); D. R. Neuville, L. Cormier, V. Montouillout, and D. Massiot, J. NonCryst. Solids 353, 180 (2007).

${ }^{23}$ J. F. Stebbins and Z. Xu, Nature (London) 390, 60 (1997).

${ }^{24}$ J. F. Stebbins, E. V. Dubinsky, K. Kanehashi, and K. E. Kelsey, Geochim. Cosmochim. Acta 72, 910 (2008).

${ }^{25}$ D. R. Neuville, L. Cormier, A. M. Flank, D. de Ligny, J. Roux, and P. Lagarde, Am. Mineral. 93, 228 (2008).

${ }^{26}$ M. Benoit, S. Ispas, and M. E. Tuckerman, Phys. Rev. B 64, 224205 (2001).

${ }^{27}$ L. Cormier D. Ghaleb, D. R. Neuville, J.-M. Delaye, and G. Calas, J. NonCryst. Solids 332, 255 (2003).

${ }^{28}$ J. F. Stebbins, in Structure, Dynamics and Properties of Silicate Melts, edited by J. F. Stebbins, P. F. McMillan, and D. B. Dingwell (Mineralogical Society of America, Washington, DC, 1995), Vol. 32.

${ }^{29}$ I. Farnan and J. F. Stebbins, Science 265, 1206 (1994).

${ }^{30}$ J. F. Stebbins, S. Kroeker, S. K. Lee, and T. J. Kiczenski, J. Non-Cryst. Solids 275, 1 (2000).

${ }^{31}$ M. J. Toplis and D. B. Dingwell, Geochim. Cosmochim. Acta 68, 5169 (2004).

${ }^{32}$ C. A. Angell, Science 267, 1924 (1995).

${ }^{33}$ J. Kozaily, These de Doctorat de 1'Université d'Orléans, 2012. 